\title{
EL IFEA (1948-2008): 60 años de investigaciones al servicio de las sociedades andinas
}

\section{Georges Lomné}

\section{(2) OpenEdition \\ Journals}

Edición electrónica

URL: http://journals.openedition.org/bifea/2770

DOI: $10.4000 /$ bifea. 2770

ISSN: 2076-5827

Editor

Institut Français d'Études Andines

Edición impresa

Fecha de publicación: 1 abril 2009

Paginación: 1-3

ISSN: 0303-7495

\section{Referencia electrónica}

Georges Lomné, «EL IFEA (1948-2008): 60 años de investigaciones al servicio de las sociedades andinas », Bulletin de l'Institut français d'études andines [En línea], 38 (1) | 2009, Publicado el 01 octubre 2009, consultado el 19 noviembre 2020. URL : http://journals.openedition.org/bifea/2770 ; DOI :

https://doi.org/10.4000/bifea.2770

\section{(c) $(1) \odot$}

Les contenus du Bulletin de l'Institut français d'études andines sont mis à disposition selon les termes de la licence Creative Commons Attribution - Pas d'Utilisation Commerciale - Pas de Modification 4.0 International. 


\section{EL IFEA (1948-2008): 60 años de investigaciones al servicio de las sociedades andinas}

\section{Georges Lomné*}

El 24 de abril de 1947, el agregado cultural de nuestra embajada en el Perú, Robert Bazin, sugirió al Ministerio de Asuntos Exteriores de Francia la creación en Lima de un «Instituto de Estudios Superiores» como un necesario complemento para la Alianza Francesa. Al lado de ésta, que no pasaba de 300 alumnos y se consagraba exclusivamente a difundir el idioma y la cultura francesa, el diplomático francés estaba deseoso de introducir en el Perú un «foco» científico francés, «arraigado en las condiciones locales y conformando su esencia propia a partir de estas». El proyecto bebía de varias fuentes. Ávido de agradecer a los latinoamericanos por la solidaridad que habían brindado a la Francia libre durante el conflicto mundial, Paul Rivet acababa de fundar el Instituto Francés de América Latina en la ciudad de México (1944) y el Instituto Francés de Port-au-Prince (1945). En el Perú, existía un contexto favorable para una creación similar debido a la presencia de dos científicos franceses vinculados a la Universidad Mayor de San Marcos: el profesor Marc Pieyre, geógrafo, y el profesor Jehan Albert Vellard, médico y biólogo.

Este último ya adquiría notorio prestigio. En 1926, a los 25 años, había empezado sus andanzas en América gracias a una larga estadía en el Brasil, en la que se consagró al estudio de las arañas venenosas. En los años 30, acompañó a Claude Lévi-Strauss en el territorio nambikwara y bororo, y luego se inclinó hacia la Antropología al escribir sobre los guayakis del Paraguay y los urus del Titicaca. En 1940, había sido nombrado director del Museo Nacional de La Paz y, en 1944, Jefe del Departamento de Zoología de la Universidad de Tucumán. En 1947, accedió al cargo de director del Museo de Historia Natural de Lima. Por ello, en mayo de 1948, le fue confiado la dirección del Centro Francés de Estudios Andinos, primer avatar del IFEA. No es de sorprenderse entonces que este científico ecléctico, heredero del espíritu de La Condamine en palabras de Raúl Porras Barrenechea, haya plasmado las «ciencias biológicas», a la par con las «ciencias geográficas» y las «ciencias antropológicas», como tarea futura de estudio para el Centro que acababa de crear. A pocos días de fundado, el 18 de mayo, el profesor Robert Hoffstetter dio una conferencia en la Alianza Francesa de Lima sobre el tema «Origen del hombre desde el punto de vista paleontológico», haciendo hincapié en la cuestión de los albores de la presencia humana

* Director del IFEA. 
en las Américas. Con ocasión de su estadía en Lima, Hoffstetter saludó la creación del instituto y apeló a la extensión de sus futuros trabajos en el Ecuador, en colaboración con la misión universitaria francesa ya radicada en este país. Huelga mencionar que no podíamos iniciar la celebración de los 60 años del IFEA sin rendir un debido homenaje a Jehan Albert Vellard y a las «ciencias de la vida», en el propio Museo Nacional de Historia Natural de Lima que dirigió hasta 1956. Esto no hubiera sido posible sin la benevolencia de su actual director, Gerardo Lamas, y la ayuda que nos brindó Rodolfo Salas Gismondi, antiguo becario del IFEA y hoy responsable del Departamento de Paleontología de dicho museo. Esta primera mesa redonda, dedicada entonces a la «riqueza paleontológica del Perú y Bolivia», tuvo lugar el 16 de septiembre de 2008 bajo la curadoría científica de Christian De Muizon, Director de Investigación en el CNRS y actual director del Departamento de «Historia de la Tierra» en el Museo Nacional de Historia Natural de París.

En su proyecto, Robert Bazin no excluía a la Etnografía ni a la Arqueología. Todo lo contrario: entre los científicos que irían a conformar el Centro Francés de Estudios Andinos en 1948, figuraban los esposos Reichlen. En aquella época, estaban por llegar al Perú mandados por Paul Rivet, nuevamente a la cabeza del Museo del Hombre en París. En sus planes, Bazin pensaba asignar a la señora Paule Reichlen la futura sección de etnografía del Centro y a su marido Henri, la sección de arqueología. Según Bazin, tal iniciativa colmaría la voluntad expresada por el famoso arqueólogo peruano, Julio César Tello, de que la etnografía y la arqueología francesa volvieran al Perú brindando una saludable competencia a la misión arqueológica permanente de los Estados Unidos. El Centro Francés de Estudios Andinos formaría entonces el núcleo, o el modelo, del Instituto Internacional que proyectaba Tello. Por lo tanto, los esposos Reichlen asistieron a la inauguración del centro el 14 de mayo de 1948 y, desde su arribo al Perú, Henri Reichlen hizo figurar la Arqueología en el corazón mismo de las actividades del Centro gracias a repetidas misiones en el departamento de Cajamarca y, de manera más general, en el norte del Perú. En 1957, cuando Olivier Dolffus llegó a Lima para asumir su cargo de agregado cultural y de director administrativo del Centro, un montón de cajas todavía ocupaba la sala de reserva del edificio Rímac, atestiguando la labor de Henri Reichlen. En un documento diplomático, fechado el 6 de mayo de 1965, al lado de los esposos Reichlen, aparece mencionada una joven antropóloga vinculada al IFEA: «la señorita Lavallée, haciendo una pasantía de investigación en nombre del CNRS». Por aquel entonces, ya habían terminado los años pioneros del «instituto Vellard», como lo llamaba Olivier Dolffus. Nombrada pensionnaire de recherches en 1974, para iniciar el programa Telarmarchay, Danielle Lavallée fue la primera arqueóloga de un listado de 35 que han pasado por el Instituto. Nos honramos de haber podido contar con su presencia y la de Michèle Julien, su colaboradora de tantos años, en la mesa redonda consagrada al «Panorama de la arqueología andina», cuya curaduría habíamos encomendado a Denise Pozzi-Scott, nuestra anfitriona en el Museo de Sitio de Pachacamac.

En 1962, con ocasión de su refundación bajo el nombre de Instituto Francés de Estudios Andinos (IFEA), Olivier Dollfus había vuelto a definir la vocación del Centro en una carta dirigida al historiador François Chevalier, sucesor de Jehan Albert Vellard:

«ser el foco de investigaciones científicas francesas en los dominios de las ciencias naturales y humanas en el Perú y en los países vecinos de los Andes».

Una tarea que este alumno de Marc Bloch desempeñó enseguida con cierto brillo: «hasta el momento, la institución nunca había definido tan nítidamente su vocación»; escribió el embajador de Francia a los dos meses de la llegada de Chevalier a Lima. El eclectismo científico de los albores daba paso a un nuevo rigor. Luego, de 1966 a 1985, a través de grandes programas, el IFEA puso la pluridisciplinaridad al servicio del desarrollo. Olivier Dollfus (1966-1972) lanzó un programa en el valle alto del río Chancay, al noroeste de 
Lima, y el otro en el valle alto del río Ambaná en La Paz (Bolivia). Pierre Usselmann (19721977) inició el programa «Loja» en el Ecuador, y François Mégard (1977-1981) organizó con la ORSTOM famosas «escuelas de campo» en geología. Jean-Paul Deler, siguiendo la vena de sus antecesores, lanzó en el Perú un gran programa de estudio sobre «Estrategias campesinas y políticas de Estado en el valle del río Cañete» y, a nivel regional, un programa sobre la integración de los barrios marginales en las metrópolis andinas. Una determinada apertura hacia las ciencias humanas y sociales se concretó bajo la dirección de Yves SaintGeours (1985-1989), pero sin renunciar, en ningún momento, a las disciplinas que habían dado sus letras de nobleza al Instituto: la Arqueología, la Paleontología, la Geología y la Geografía urbana. Sus sucesores, Christian de Muizon (1989-1996), Georges Pralong (19961999), Jean-Joinville Vacher (1999-2003) y Henri Godard (2004-2007), se conformaron con esta amplia apertura disciplinaria. Por lo tanto, las tres mesas redondas temáticas que complementaron la celebración de los 60 años no podían traducir la infinita riqueza del trabajo llevado a cabo por 343 investigadores. Quisieron, más bien, plantear unas directrices de trabajo para el futuro, entre muchas otras. La primera enfocó la necesidad de abrir nuevas «Perspectivas en Antropología Amazónica». Esta mesa estuvo a cargo del antropólogo Jean-Pierre Chaumeil, Director de Investigación en el CNRS y actualmente puesto a disposición del IFEA. La segunda, a cargo de la etnóloga Carmen Salazar-Soler, investigadora del CNRS, y de Carlos Iván Degregori, politólogo y director del Instituto de Estudios Peruanos (IEP), enfatizó los avances de la «Antropología del Estado en los países andinos». La tercera y última, a cargo del geógrafo Jean-Paul Deler, Director de Investigación en el CNRS, trató de la «Evolución de Lima y su proceso de metropolización globalizado». Al finalizar con una de las temáticas de más largo alcance en la vida misma del Instituto, culminó así la celebración con broche de oro. A continuación, encontrarán las actas de la primera de estas mesas, bajo la forma inédita de un dossier. 